\title{
Melanophores inside Frogs
}

\section{Elena S. Pshennikova, Anna S. Voronina*}

\author{
A.N. Bach Institute of Biochemistry, Research Center of Biotechnology RAS, Moscow, Russia \\ *voronina_a@mail.ru
}

Keywords: melanocytes, melanophores, frogs, vertebrates, embryogenesis, inner connective tissues.

\begin{abstract}
Melanocytes/melanophores were known for some decades as pigment cells in skin. The origin of these cells in embryogenesis from neural crest cells is actively investigated now. Some melanocytes/melanophores were described inside adult vertebrates. Historically, these internal melanocytes have been largely ignored, until recently. In frogs, the melanophores populate not only the skin, but all the inner connective tissues: epineurium, peritoneum, mesentery, outer vascular layer and skin underside. In adult avian, melanocytes were also found in visceral connective tissues, periostea, muscles, ovaries and the peritoneum. In mammals and humans, melanocytes are also revealed in eyes, ears, heart and brain. A black-brownish pigment, which can be found in brains of humans and some mammals, was called neuromelanin. Currently, attempts are being made to treat neurodegenerative diseases and various nerve injuries with medications containing melanin. In this micro-review, we wanted to remind again about the inner melanophores on visceral organs and lining blood vessels and nerves, their importance in organisms resistance to adverse environmental factors.
\end{abstract}

\section{Introduction}

Melanocytes are the cells carrying melanin pigments. The melanins are insoluble polymers, the products of tyrosine amino acid polymerization and oxidative transformations. Inside the melanocytes, the melanin is packed in granules - melanosomes. These are specialized intracellular membrane-coated organelles that originate from the endoplasmic reticulum. In the process of differentiation the melanosomes are generated in melanoblasts - the melanocytes progenitors. The pigment melanin is produced in melanosomes in a complex process called melanogenesis [1]. The melanocytes of poikilotherms_are commonly called melanophores. Melanophores differ from melanocytes in their ability to move and rearrange the pigment granules inside of them. It was investigated in both frog tadpole cutaneous and mesentery melanophores [2, 3]. Along with other pigment-containing cells (iridophores, xanthophores, guanophores) the melanophores are responsible for adaptive changes in amphibian coloration. Due to its oxido-reduction potential and stable free radical status, the melanin can protect the melanin-containing structures and neighboring tissues from red-ox stressing processes, harmful for the normal metabolism. It provides photo- and radioprotection.

\section{In Embryogenesis}

In the vertebrate embryogenesis, melanocytes originate from the neural crest cells (NCCs) [4]. The pluripotent trunk NCCs generate bipotent neuron/glial and glial/melanogenic cells-progenitors [5]. The time and paths of their migration are dependent on the future fate choice. The migrating NCCs can follow a dorso-lateral path between the ectoderm and somites, or a ventro-medial path from the neural tube inside developing somites. The earlier NCCs mostly follow the ventro-medial path and differentiate into neurons and glia, contributing to future peripheral and autonomic neural systems, while the later waves of migration follow the dorso-lateral path and generate the pigment cells lineage including melanocytes. These melanocytes reach the epidermis, hair and other target tissues. The cooperative cells interactions, the cytoskeleton activity, negative and positive regulations directly influence the complicated pattern of the NCCs migration. Some times they 
migrate one-by-one in chain and so the path can be traced. The paths of migration are determined by a set of permitting extracellular matrix components, like laminins, versicans and fibronectins which facilitate the proper NCCs migration.

The melanoblasts in Silkie fowl were shown to lose their spatial path restriction, and in addition to the dorso-lateral path they migrate to bones, cartilage, muscles, and connective tissues [6]. These melanocytes then undergo a unique differentiation process and cause the internal tissues of Silkie fowl to become hyperpigmented. Recently it was shown in Zebrafish that the pigment cells progenitors derived from the neural crest, still retained the multipotency in adults. These postembryonic progenitors are associated with the peripheral neural system. They are flexible enough to give rise to different pigment (melanophores, iridophores and xanthophores) and neural cells (neurons and glia) [7].

An interesting concept of the melanocytes origin was proposed by Adameyko and collaborators [8-13]. According to this concept, during the avian and mammals embryogenesis, the melanocytes differentiate from the multipotent Schwann cells progenitors (SCPs) derived from the stem NCCs. The SCPs migration occurs along the growing axons of the peripheral neurons. At the moment the NCCs associate with the emerging neurons axons, they are considered as the SCPs. The expansion of the SCPs and number of melanoblasts happens mainly along and inside the nerves, terminated in specific dermal sites. Thus the growing nerves may be considered as niches for the stem cells and cells-progenitors, which give rise to numerous cells types, including glial Schwann cells, neuro-endocrine cells, parasympathetic and gut neurons, endoneural fibroblasts, melanocytes and others.

\section{In Adults}

The melanophores distribution patterns in adult amphibians are studied mainly in the skin, for they determine the animal coloration and ensure the defense from radio- and other harmful agents. In amphibian skin, the aggregation of melanosomes in perikaryal area of melanophores (contraction) results in brightening of animal marking (in the dark), while their diffusion over melanophores cytoplasm and dendrites (dispersion) leads to animal browning in the light. The adaptation of animals to the white ground is provided by the contraction, but in the adaptation to the dark ground there occurs the dispersion [2]. These processes are regulated by the melanocytestimulating hormone and melatonin. In addition to cutenious, melanophores were revealed also in frog pericardium and blood vessels at the basis of the heart; heart; lungs; stomach; middle intestine; rectum; intestinal mesentery; kidney and renal blood vessels; testes; fatty bodies; urinary bladder; lumbar nerve plexus; and lumbar parietal peritoneum [14-16].

Here we demonstrate (Figs. 1-3) the melanophores patterns inside the adult frogs Rana temporaria and Xenopus laevis. All the inner connecting tissues appeared to be spangled with these pigment cells. 


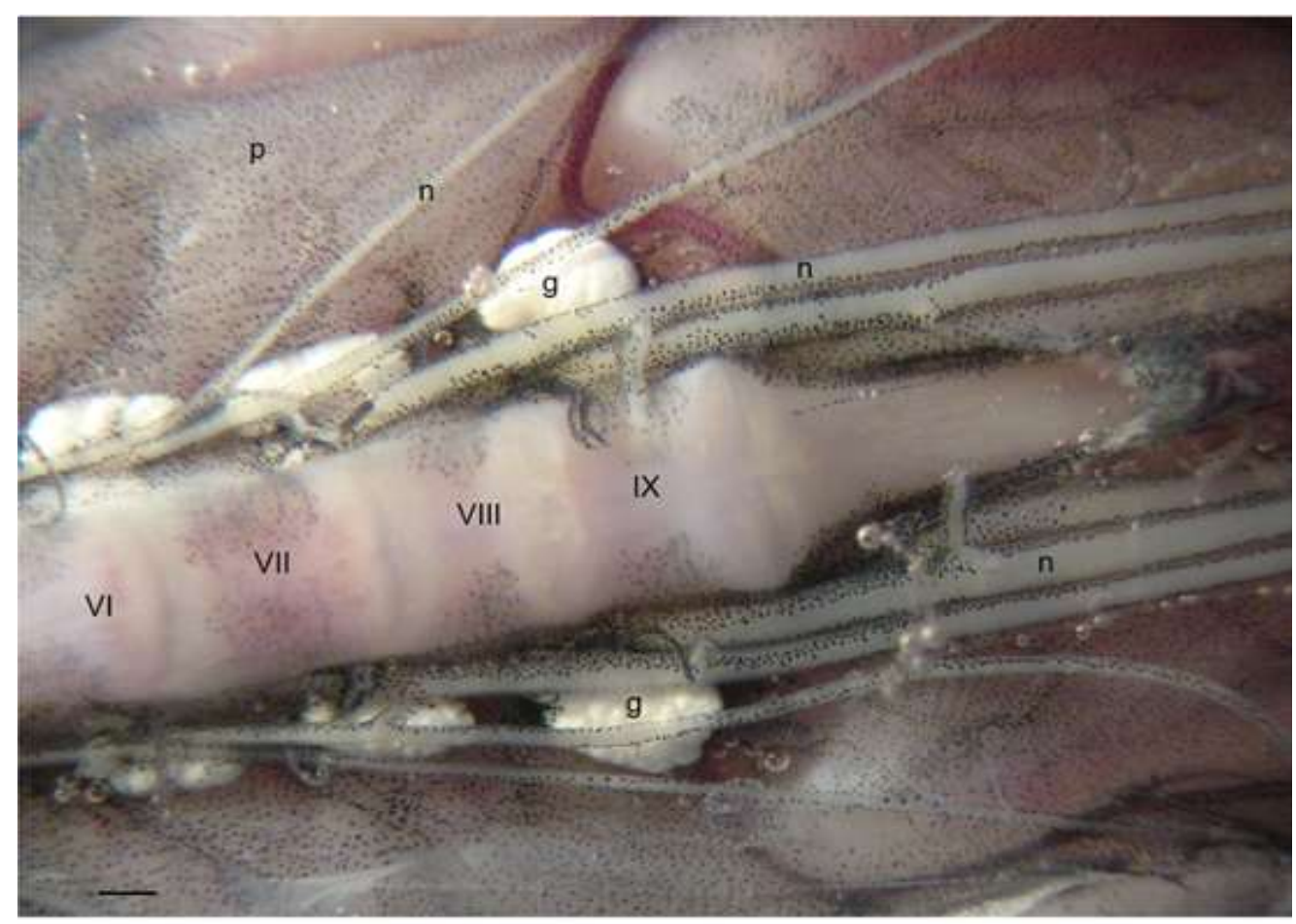

Figure 1. A fragment of a dissected Rana temporaria with the lumbar vertebrae exposed. Ventral view. Roman numeral - vertebrae numbers (VI - IX); $\mathrm{n}$ - spinal nerves; $\mathrm{p}$ - peritoneum; $\mathrm{g}$ - a bulge of endolymphatic duct, harboring spinal radicule ganglions and lime crystals. Scale bar $-1 \mathrm{~mm}$.

The Fig. 1 shows a fragment of a dissected Rana temporaria without any treatment. The Fig. 2 combines the samples of several tissues from different specimens at larger magnifications. It is seen (Fig. 2 A, B, C, G) that the surface of the nerve trunks is dotted with chains of pigment cells - melanophores. The melanophores are associated particularly with the outer envelope (epineurium) that is clearly visible (Fig. 2B) when the envelope was removed mechanically with a needle. There in inner nerve fibers, in the perineurium and endoneurium, the pigment cells were not revealed. It is well known that the nerve outer envelope consists of dense connective tissue and carries blood and lymphatic vessels. The Fig. $2 \mathrm{C}$ shows a larger magnification of a fragment of isolated epineurium with melanophores chains in it. As shown in the Figs. 1 and 2D, the frog peritoneum is also thickly strewn with melanophores. A large magnification of the mesentery sample allowed to discern fibers, probably of collagen and elastin, bedding the melanophores (Fig. 2F). There over the blood vessels (red in Fig. 2D) and nerves (or it may be lymphatic vessels, white in Fig. 2D), associated with the peritoneum, melanophores are also revealed. Over the muscles (Fig. 2E), the melanophores form chains, marking the muscle-binding nerves. The branching nerve fibers and/or lymphatic vessels are also revealed at the skin underside, to much extent due to melanophores chains marking them (Fig. 2H and I). Melanophores are also observed over the connective-tissue envelope around the lumbar vertebrae (Fig. 1). Fig. 3 demonstrates the Xenopus laevis sciatic nerve fragments. Like that of Rana temporaria, the trunk nerve surface is covered with numerous melanophores of different shapes and with dendrites as well. The major magnification allowed to reveal the pigment cells over the connective-tissue fibers in the isolated epineurium preparation. 

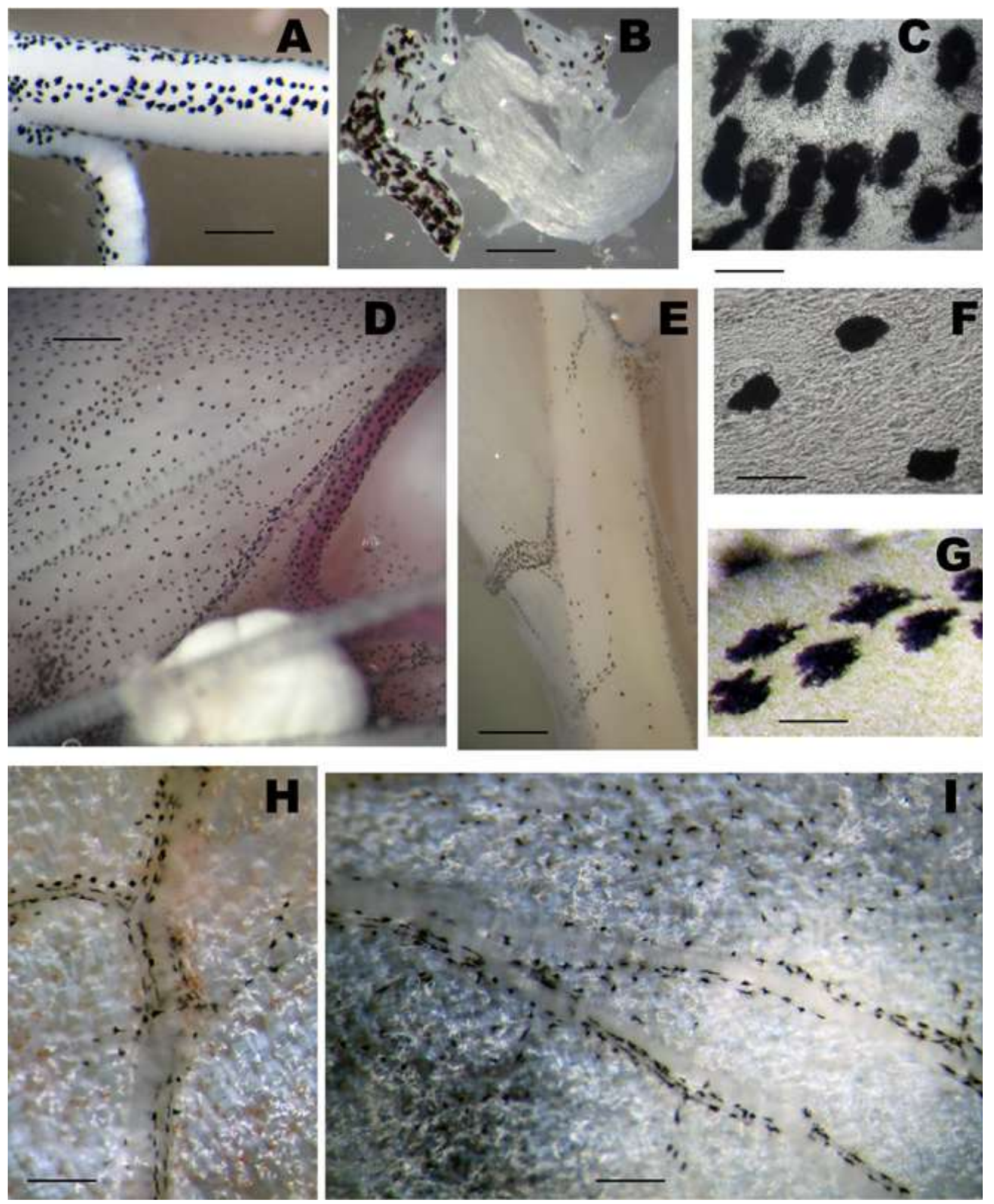

Figure 2. Melanophores within different tissues of Rana temporaria. A - a fragment of sciatic nerve with chains of melanophores on it. B - a fragment of sciatic nerve with no melanophores below the epineurium. $\mathrm{C}$ - a micrograph of melanophores in isolated epineurium. $\mathrm{D}$ - peritoneum with blood vessel and nerves. $\mathrm{E}$ - muscle with a binding nerve. $\mathrm{F}$ - a micrograph of melanophores in the mesentery. $\mathrm{G}$ - chains of melanophores with dendrites on the nerve envelope. H and I fragments of the inner side of frog skin with melanophores, marking vessels or nerves. Scale bars: $\mathrm{A}$ and $\mathrm{B}-700 \mu \mathrm{m} ; \mathrm{C}, \mathrm{F}$ and $\mathrm{G}-100 \mu \mathrm{m} ; \mathrm{D}-1.5 \mathrm{~mm} ; \mathrm{H}$ and $\mathrm{I}-1 \mathrm{~mm}$. 

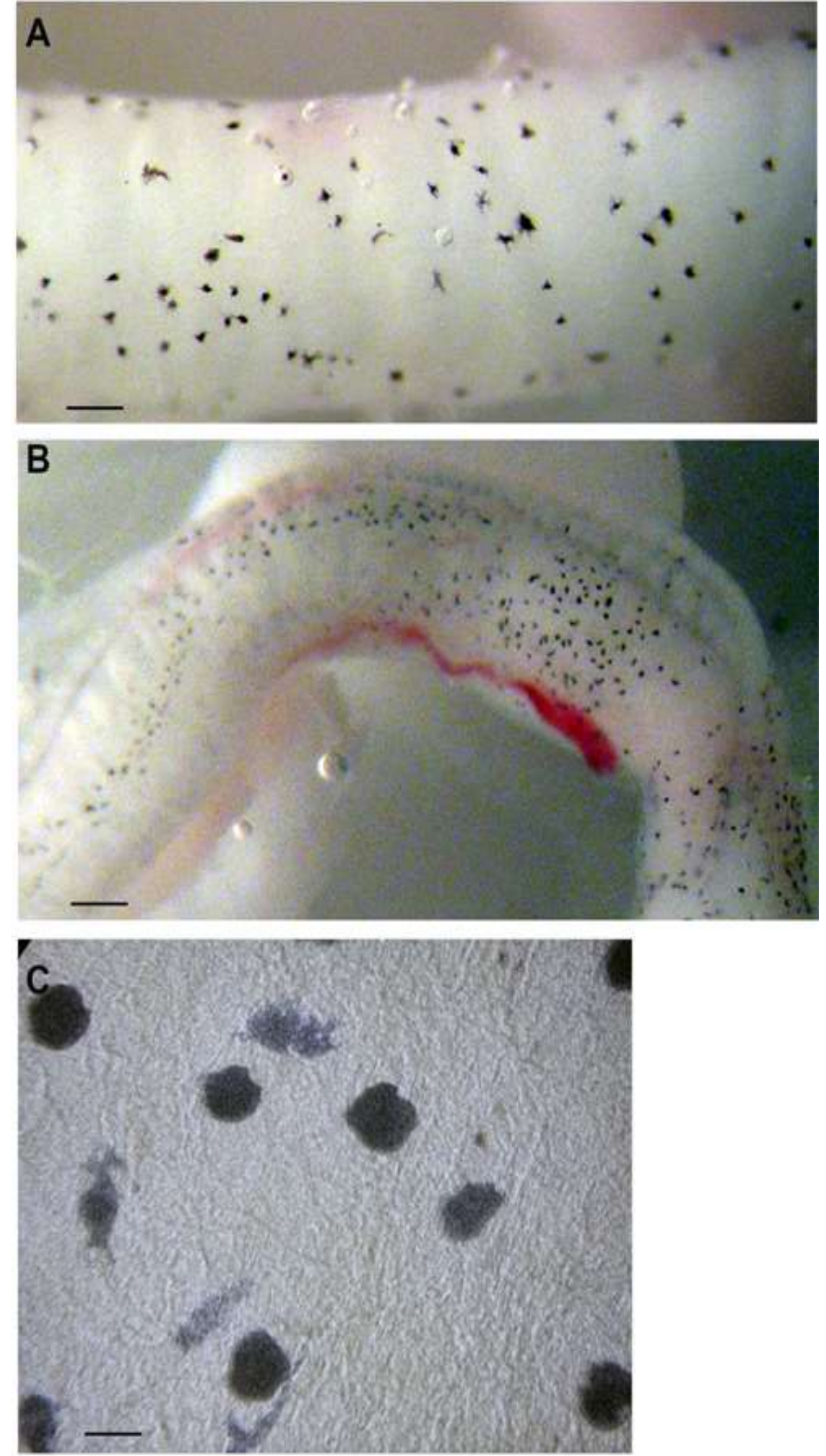

Figure 3. Melanophores on the Xenopus laevis nerve. A and B - fragments of sciatic nerves. Melanophores and blood vessels are seen. $\mathrm{C}$ - a micrograph of melanophores in isolated epineurium. Scale bars: A $-150 \mu \mathrm{m}, \mathrm{B}-300 \mu \mathrm{m}$ and $\mathrm{C}-30 \mu \mathrm{m}$.

Hence, we can see that in frogs, the melanophores populate all the inner connective tissues: epineurium, peritoneum, mesentery, outer vascular layer and skin underside. As it is known, all these connective tissues contain the collagen and elastin fibers. They probably facilitate the melanophores migration or/and anchoring. The question is why the melanophores harboring inside the animal are so necessary. Probably, the frog skin is too much transparent and so innards and 
nerves in particular, are to be protected from the harmful impacts of light. However, the presence of internal melanophores in non-transparent animals suggests that these cells have additional functions. The Brazilian authors described systemic effects of external ultraviolet radiation on internal melanin pigmentation, melanomacrophages and melanophores in frogs and thus provided a functional explanation to the presence of internal pigmentation [17]. Melanin can act as an antioxidant and protect against DNA damage and as immunomodulator. The climatic variables (temperature, UV and photoperiod) influence the coloration of internal organs of anurans [18]. Melanin pigmentation on the surface of organs of amphibians has an adaptive function conferred by the protective functions of the pigment. But most importantly, the internal melanin seems to respond differently to climatic variables depending on the species lineage and locality. DNA damage caused by UV were more pronounced in non-pigmented than in pigmented animals; the frequency of immune cells differed between pigmented and non-pigmented tadpoles. UV exposure increased mast cells and DNA damage in erythrocytes in both pigmented and non-pigmented tadpoles, while leukocytes decreased after UV exposure. Leukocyte responses were faster in nonpigmented animals, supporting the hypothesis that melanin is involved in the initial innate immune response [19]. Probably, melanophores may also protect from active forms of oxygen and other free radicals - results of the normal metabolism.

There are very few works on fish inner melanophores. Changes in internal color in many species of fish can be due to responsive peritoneal chromatophores and the degree of such a response correlates with levels of body transparency [20].

In adult avian, melanocytes were also found in visceral connective tissues [6]. Under normal physiological conditions, Silkie fowls contain a large amount of melanin in their skin, periostea, muscles, ovaries, and other internal organs and tissues [21, 22]. Excess accumulation of melanin was observed in the visceral peritonea of the Huiyang Bearded chicken. The study provided the histological and physical-chemical evidence to prove that black abdomen was due to a high amount of melanin accumulation in the peritoneum [23]. In mammals the bulk of melanocytes are settled in skin, they are also revealed in eyes, ears, heart [24]. We failed to find any melanocytes on the murine epineurium (data not shown).

In humans, there was the pigmentation in meninx and no pigmentation visible in the lining tissues of the pleural and peritoneal cavities [25]. A black-brownish pigment, which can be found in brains of humans and some mammals like primates, cows and horses, was called neuromelanin [26, 27]. Furthermore, it was described that the pigment was normally accumulated in dopaminergic neurons during aging [28]. It is of special interest because in Parkinson's disease, pallor of the substantia nigra pars compacta can be seen, due to the depletion of dopaminergic neurons containing neuromelanin [27, 29]. Currently, attempts are being made to treat neurodegenerative diseases and also various nerve injuries with medications containing melanin [30].

The presence of such internal pigmentation is puzzling as it is hidden from sight. While there are enormous amount of studies and data on skin chromatophores, from the fine details of the motile machinery to animal behavior [31], the internal melanocytes have historically been largely ignored, until recently. Given that cutaneous chromatophores, retinal pigment cells, otic melanocytes as well as peritoneal melanocytes, can respond to external stimuli, these cells appear to share a relationship with environmental sensation. By providing communication and awareness of the surroundings, melanocytes in non-cutaneous tissues, such as in the peritoneum, may therefore be more connected to animal behavior than previously considered.

The presence of internal melanocytes in non-transparent species suggests that there are additional function(s) of these cells. For example, they may function as waste deposits for accumulated melanin, participate in the innate immune system, function as antioxidants and /or possibly help to shield gonadal tissue from DNA damage, as speculated [20, 31-33].

Nevertheless, it appears that melanocytes are not simply melanin-producing cells and may have some other physiological significance. It has been proposed that melanocytes act as local "stress sensors" in the epidermis [34], and provide communicatory links with several different systems. For example, their close anatomic associations with nerve endings [35] and their ability to 
produce neuropeptides and neurotransmitters suggest their role as neuroendocrine cells and thus, as a key component of a communication pathway between the skin and the central nervous system.

\section{Animals and Ethical Clearance}

Adult frogs were taken from the laboratory bands of the Shemyakin-Ovchinnikov Institute of Bioorganic Chemistry (Moscow, Russia). All animal experiments were performed in accordance with guidelines approved by the Animal Committee and handled in accordance with the 1986 Animals (Scientific Procedures) Act and Helsinki Declaration.

The dissected frogs and tissue samples were photographed directly or after MEMFA fixation. In total, there were taken 2 males and 1 female of Rana temporaria at different seasons and 3 Xenopus laevis males.

\section{Conflicts of Interest}

The authors have no conflicts of interest to declare.

\section{Acknowledgements}

We would like to thank the Shemyakin-Ovchinnikov Institute of Bioorganic Chemistry (Moscow, Russia) for frogs kindly donated.

This study was supported by Russian Federal Agency of Scientific Organizations N 01042018-0022.

\section{References}

[1] I.F. Videira, D.F. Moura, S. Magina, Mechanisms regulating melanogenesis, An. Bras. Dermatol. 88(1) (2013) 76-83.

[2] E.N. Nikeriasova, V.A. Golichenkov, Dynamics of the redistribution of pigmented granules in the dermal melanophores of anuran larvae. 2. Aggregation, Ontogenez. 19(6) (1988) 618-625.

[3] E.S. Kirpichnikova, L.B. Levinson, The workshop on General histology: textbook, Graduate school, Moscow, USSR, 1962, pp. 64-65. (in Russian)

[4] J.M. Newbern, Molecular control of the neural crest and peripheral nervous system development, Curr. Top. Dev. Biol. 111 (2015) 201-231.

[5] A.J. Thomas, C.A. Erickson, The making of a melanocyte: the specification of melanoblasts from the neural crest, Pigment Cell Melanoma Res. 21(6) (2008) 598-610.

[6] C.D. Faraco et al., Hyperpigmentation in the silkie fowl correlates with abnormal migration of fate-restricted melanoblasts and loss of environmental barrier molecules, Dev. Dyn. 220 (2001) 212-225.

[7] A.P. Singh, et al., Pigment cell progenitors in zebrafish remain multipotent through metamorphosis, Developmental Cell. 38(3) (2016) 1-15.

[8] I. Adameyko, et al., Schwann cell precursors from nerve innervation are a cellular origin of melanocytes in skin, Cell. 139(2) (2009) 366-379.

[9] I. Adameyko, F. Lallemend, Glial versus melanocyte cell fate choice: Schwann cell precursors as a cellular origin of melanocytes, Cell. Mol. Life Sci. 67(18) (2010) 30373055 .

[10] C.D. Van Raamsdonk, M. Deo, Links between Schwann cells and melanocytes in development and disease, Pigment Cell and Melanoma Research. 26(5) (2013) 634-645. 
[11] M.E. Kastriti, I.Adameyko, Specification, plasticity and evolutionary origin of peripheral glial cells, Current Opinion in Neurobiology. 47 (2017) 196-202.

[12] J. Petersen, I. Adameyko, Nerve-associated neural crest: peripheral glial cells generate multiple fates in the body, Current Opinion in Genetics \& Development. 45 (2017) 10-14.

[13] A. Furlan, I. Adameyko, Schwann cell precursor: a neural crest cell in disguise? Dev Biol. (2018). In press. Doi: https://doi.org/10.1016/j.ydbio.2018.02.008.

[14] E.O. Zagal'skaia, The vascular melanocytes of the pia mater and mesentery of the small intestine in the frog: structure and functions, Tsitologiia. 36(8) (1994) 796-801.

[15] L. Franco-Belussi, et al, Pigmentation in anuran testes: anatomical pattern and variation, The Anatomical Record. 292 (2009) 178-182.

[16] L. Franco-Belussi, et al, Visceral Pigmentation in Three Species of the Genus Scinax (Anura: Hylidae): Distinct Morphological Pattern, The Anatomical Record. 295 (2012) 298-306.

[17] L. Franco-Belussi, H. Nilsson Skold, C. de Oliveira, Internal pigment cells respond to external UV radiation in frogs, J. Exp. Biol. 219(Pt 9) (2016) 1378-1383.

[18] L. Franco-Belussi, D.B. Provete, C. de Oliveira, Environmental correlates of internal coloration in frogs vary throughout space and lineages, Ecol. Evol. 7(22) (2017) 9222-9233.

[19] L. Franco-Belussi, L.Z. Fanali, C. de Oliveira, UV-B affects the immune system and promotes nuclear abnormalities in pigmented and non-pigmented bullfrog tadpoles, J. Photochem. Photobiol B. 180 (2018) 109-117.

[20] H. Nilsson Skold, P.A. Svensson, C. Zejlon, The capacity for internal colour change is related to body transparency in fishes, Pigment Cell and Melanoma Research. 23(2) (2010) 292-295.

[21] S. R. Muroya, I.T. Nakajima, K. Chikuni, Molecular characteristics and site specific distribution of the pigment of the silky fowl, J. Vet. Med. Sci. 62 (2000) 391-395.

[22] S. R. Chen et al, Isolation and characterization of natural melanin derived from silky fowl (Gallus gallus domesticus Brisson), Food Chem. 111 (2008) 745-749.

[23] J. Wang et al, Accumulation of melanin in the peritoneum causes black abdomens in broilers, Poult. Sci. 93(3) (2014) 742-746.

[24] F.C. Brito, L. Kos, Timeline and distribution of melanocyte precursors in the mouse heart, Pigment Cell and Melanoma Research. 21 (2008) 464-470.

[25] M.H. Goldgeier et al, The Distribution of Melanocytes in the Leptomeninges of the Human Brain, J. Investigative Dermatology. 82(3) (1984) 235-238.

[26] M. Bazelon, G.M. Fenichel, J. Randall, Studies on neuromelanin. I. A melanin system in the human adult brainstem, Neurology. 17(5) (1967) 512-519.

[27] H. Fedorow et al, Neuromelanin in human dopamine neurons: comparison with peripheral melanins and relevance to Parkinson's disease, Prog. Neurobiol. 75 (2005) 109-124.

[28] G.M. Fenichel, M. Bazelon, Studies on neuromelanin. 2. Melanin in brainstems of infants and children, Neurology. 18 (1968) 817-820.

[29] S. Plum et al, Combined enrichment of neuromelanin granules and synaptosomes from human substantia nigra pars compacta tissue for proteomic analysis, J. Proteomics. 94 (2013) 202 206.

[30] O.V. Gevorkyan et al, Bacterial melanin promotes recovery after sciatic nerve injury in rats, Neural Regeneration Research. 10(1) (2015) 124-127.

[31] S.Aspengren et al, New insights into melanosome transport in vertebrate pigment cells, Int. Rev. Cell. Mol. Biol. 272 (2009) 245-302. 
[32] H. Z. Hill, The function of melanin or six blind people examining an elephant, Bioessays. 14 (2000) 49-56.

[33] S. Ito, Melanins seem to be everywhere in the body, but for what? Pigment Cell and Melanoma Research. 22(1) (2009) 12-13.

[34] A. Slominski, R. Paus, D. Schadendorf, Melanocytes as "sensory" and regulatory cells in the epidermis, J. Theor. Biol. 164(1) (1993) 103-120.

[35] M. Hara et al, Innervation of melanocytes in human skin, J. Exp. Med. 184 (1996) 13851395. 